\title{
The problem of the concept of the living machine according to Samuel Alexander's emergentism
}

The concept of a living being as a kind of living machine is widespread and well-known. If it is only a metaphor, it does not mean much; however, if otherwise, there is a severe conceptual problem since the living part of the concept always indicates the notorious notion of vitalism. The question is how can living machines be really different from lifeless machines without the concept of vitalism?

According to Samuel Alexander, the problem arises from the traditional usage of the concept of mechanical which is confused both with the concept of something is determinated and with the concept of material; furthermore, the latter concept is defined against the Cartesian concept of mind and not on its own. Alexander's point is that the difference between lifeless machines and living beings lies not in a vital substance or a non-mechanical principle but in an emergent mechanical quality called life which simple machines lack.

Keywords: emergentism, vitalism, machines, matter vs. mind dichotomy, Alexander

Author Information

Daniel Paksi, http://filozofia.bme.hu/ensite/staff/daniel paksi

How to cite this article:

Paksi, Daniel. "The problem of the concept of the living machine according to Samuel Alexander’s emergentism.” Információs Társadalom XX, no. 4 (2020): 37-47. 


\section{Introduction}

In my paper-based on my talk at the Budapest Workshop on Philosophy and Technology 2019 conference-I will shortly investigate the well-know concept of the living machine from an unusual point of view called emergentism.

Emergentism is established by Samuel Alexander exactly a century ago in 1920 by his Space, Time, and Deity. However, for clarity it is perhaps worth to note that in the mainstream and thus non-emergentist philosophical traditions it is usual to claim (see, for example, Brian McLaughlin's famous and influential paper The Rise and Fall of British Emergentism (1992)) that the first emergentist was John Stuart Mill thanks to his A System of Logic (1943), and the term comes from George Henry Lewes's book The Problems of Life and Mind (1875). It is important to emphasize, however, that from Alexander's point of view, Mill or Lewes was not emergentist at all; they just used few terms, most notably "homeopathic laws" and "heteropathic laws" by Mill which are very similar to a real emergentist differentiation of non-emergent and emergent relations between ontological levels, especially to C. D. Broad's "basic laws of nature" and "special laws of nature." (Broad 1925) However, these differentiations are only small, marginal parts of Mill's or Lewes' philosophy and most of all they clearly did not want to create a new emergentist ontology as Alexander, Broad, or Lloyd Morgan (1923) did.

Emergentism is an ontological concept which stands between the well-know and widespread concepts of dualism and materialism. Dualism claims that everything is composed of two substances, matter and mind-or with older terms, body and soul;- -while materialism claims that everything is composed of only matter. According to these concepts, reality is fundamentally substantial.

However, the point of emergentism is that reality is fundamentally not substantial but emergent: reality is dynamic, reality always unfolds itself; therefore, substances are but the consequence of the development of reality. Matter, for instance, can be regarded as the composite substance of the living body but it is not the substance of reality itself, it cannot be regarded as a substance on its own because it is as well a consequence of the unfolding or development of reality as any living body is the consequence of the unfolding or development of reality called evolution. One can say that matter is the consequence of cosmologic evolution especially of the Big Bang.

Emergentism stands between dualism and materialism because concerning the human person, similarly to dualism, it claims that there is a body and there is a soul-or matter and mind;-as well as similarly to materialism, it claims that there is only one composite substance of the human person which is matter: the soul or mind is an unfolding emergent reality by time in the (especially neurological) spaces of this material substance, it is based and depends on this substance, it is not a substance on its own.

In this paper I will not give detailed analysis of Alexander's Space, Time, and Deity or his general philosophy, I will be focused merely on the topic. 
You can read easily accessible and correctly founded comprehensive critiques of his work in Broad's Prof. Alexander's Gifford Lectures (1921a, 1921b) or in Stout's The Philosophy of Samuel Alexander (1940a, 1940b) as well as in my book Personal Reality, especially in chapter 5: Space, Time, and Matter (2019).

\section{The term living machine}

The living machine is, of course, a well-known phrase. But what does it mean? Why it is so well-known? I believe it is well-known because it tells so much by a simple term which expresses both the essential difference and the similarity between machines and living beings; and exactly this contradiction is the reason that its meaning is problematic.

So, the term living expresses the clear and essential difference between life-less machines and living beings, while the term machines claims that in a sense machines and living being are still the same. They are the same in a sense because both of them are mechanical, and both of them have a determinative structure - that is, both of them follows the fundamental physical laws and perhaps certain more specific mechanical laws which determinate their functioning.

Consequently, in the sense of this similarity, the term machines means mechanical and not machines in the literal sense-while the term living expresses exactly the difference over and above this identity of mechanical structure that living beings are not just mechanical but they have certain original, unique features like, for example, the ability of reproduction and a kind of autonomy that they are not under the control of man, they are not created by man but they are active and evolving on their own. So, with a Latin term, they are vital, vital machines.-And, of course, this difference very fast could imply vitalism, which is, as we know well from biologists, unscientific, obscure, unacceptable, etc.

But what is wrong with vitalism? Why it is so unscientific? The answer is that because it implies some kind of innate, nonmaterial power (élan vital as we usually and very wrongly say); so, it basically means that living beings possess some kind of nonmaterial design which, of course, very easily could imply some kind of divine origin, some kind of creation. Thus, as machines are created by man, vital machines are created by a higher nonmaterial forcewhich, by the way, was, of course, the original idea for Descartes or Newton in the beginning of modern mechanical science in the 17th century and became a problem only at the end of the 19th century.

It is worth to notice that we have started with the fact that living beings are vital machines because they are not created by man as machines did; thus, they possesses some unique features compared to life-less machines. But now the problem is that this difference between life-less machines and living beings easily could imply that, then, they are created by some kind of nonmaterial, higher force-which is not scientific. 
Usually, one of the main points of emergentism is to evade this trap (for example, Alexander and Polanyi, see his argument in Personal Knowledge (1962, especially in 382-400)); however, a few emergentist, most notably Morgan acknowledges a kind of divine involvement (Morgan 1923) which is, of course, a perfect ground for non-emergentist who usually do not accept that the position of emergentism is sound in this regard. I personally think that it is (Paksi 2019, especially in Vol. 2, 31-97).

\section{The two senses of mechanical}

So, what is the problem? According to Samuel Alexander, the problem is that we use the term mechanical in two different senses (Alexander 1920 II., 65-66). And we, of course, unnoticed mix up these senses. And these two senses do not include the sense I used a minute ago that mechanical sometimes only means machine without any more specific meaning. This is the Polanyian point and I will come back shortly to this third sense at the end of my paper.

The first meaning of mechanical is simply material. Which is mechanical that is material. And this, of course, implies that living machines are not just material. They are vital. This is, of course, an ontological claim, as, in this sense, we try to understand the composition of living machines.

At this point, Alexander, as many others, speaks about and argues against Hans Driesch who famously claimed based on his experiments that living beings are composed both of matter and of a vital entelechy which is the fundament or reason of such unique features of living beings as reproduction, regeneration, etc. (Alexander 1920 II., 64). Thus, they are not just material machines (similarity) but vital organism (difference). The entelechy is, of course, an Aristotelian concept from before Cartesian and Galilean mechanical science.

The old problem at this point is this. If we use only Cartesian or Galilean, that is, modern mechanical physics and chemistry, we will never be able to explain the unique features of living beings - the general and practical ("positive") methods of Galilean science is simply not applicable to these unique, original features (with other words, the reduction of these unique features does not work). Therefore, if we want to be consistent that this is science and nothing else (and, of course, Galilean science covers everything in the universe), then, we will have to deny the reality of every uniqueness of living beings - that is, we have to deny and ignore clear biological facts. But, on the other hand, if we want to keep these clear facts in science, we will have to use such unique principles like vital forces and entelechies which, unfortunately, cannot be reconciled with mechanical science; and, of course, both ways are really problematic. So, this was the ontological part of the problem. The other part is, of course, the epistemological one.

The other, second meaning of mechanical, according to Alexander, is simply determinated: both in the sense of structure, which applies to machines and living machines, too, and in the sense of reproduction and autonomy in case 
of living beings. In this sense, there is no ontological content in the concept of life-less mechanical machines and living mechanical machines, either. It only claims that there are such mechanical structures and laws which determinate the functioning and behaviour of both machines and living beings; and this structure and its laws can, of course, scientifically analyzed and explained in both cases,- - there is neither any fundamental difference, nor any conceptual or scientific problem in this epistemological sense.

However, the ontological question, that what is the ultimate reason between the determinate order and structure of machines and the determinate order, structure, and reproduction, autonomy, and any other unique features of living beings is still a valid question which necessarily arises. The important point here is not the denying of this deeper question but that these are two different questions, two different senses in which we use this concept. And the real question, our real problem is that why we do not clearly differentiate between these two different senses of the concept of mechanical. Alexander's answer is that we think in a false dichotomy.

\section{The false dichotomy}

This is, of course, the well-known ontological dichotomy between matter and mind created by René Descartes and modern Galilean mechanical science against the Aristotelian hierarchical concept of reality. In Aristotelian science, there was also a kind of dichotomy between matter and form but this was only a logical dichotomy not a real one in a sense that real things are necessarily composed both of matter and form. In Aristotelian science, mind is a kind of higher level form in the hierarchical order of reality and not the antithesis of matter. Mind, therefore, is integrated or organised part of the human body; moreover, it can even be argued that the mind as such cannot even be separated from the body - that is, against the teachings of Christianity and Plato, the mind cannot survive the death of the body.

However, in the modern concept, as a matter of fact, exactly because of this historical/religious reason, the whole point of the concept of mind is that it is another both logically and existentially different substance which can be separated from matter-that is, it can, according to the teachings of Christianity, survive the death of the material body. Consequently, the body is material and determinated by its mechanical structure, while the mind is nonmaterial and not determinated by any mechanical structure of the body but, on the contrary, can survive the death of the body. The clear difference between the two senses, material and determinated, between the ontological and the epistemological sides evaporates - there remains only the thesis of eternal minds (souls) and its mortal antithesis of matter (body).

It means that there is no essential (ontological) difference between a lifeless rock (body) and a full of life frog (body) because both of them are merely 
body, merely matter; essential difference comes only from mind (soul); however, living beings have no minds or souls created by the image of God, merely man has.

Aristotle was clearly wrong in case of physics and chemistry, there is no place for minds or forms in physical sciences; however, in life sciences this is not the case at all. I mean that in physical sciences the modern concept of mechanical and the only composite substance of matter was worked so well, especially before the 20th century, but in life sciences it did not,--exactly, of course, because of the unique features of life, because of which we differentiate between life-less machines and living machines. Therefore, if we think in the modern dichotomy of matter and mind, it will necessarily mean that, in life sciences, we need another composite substance over and above matter and its mechanical laws, which is not mechanical, which is not determinated but like mind, I mean "little minds" in the bodies of living beings-ghost in the machine-explain the unique features of life. This is the conceptual origin of the modern concept of vital force or vital substance or Driesch's entelechyalthough he uses Aristotle's concept, it is, in fact, quite different, due to this modern dichotomy, it has an absolutely modern meaning and not at all an Aristotelian one.

So, the point is this: we, first, realised, that Aristotle was wrong concerning physical sciences, there is no place for forms or minds there; then, according to the teachings of Plato and Christianity, we sharply separated matter and body, on the one hand, and mind or soul which can survive the death of the body, on the other one. Now, I mean in the 20th and the 21st century, we do not believe in eternal minds and Cartesian dualism anymore, but we still think in this dichotomy between matter and mind, where the concepts of mechanical, material, and determinative order basically means the same-of course, we sense that these are not the same concepts but, unfortunately, there is no clear, philosophically grounded difference between the meanings.

Therefore, you have two choices: (1), in theory, deny or at least ignore the unique features of living beings, which, in practice, cannot be done at all, so you will not be coherent at all; or (2) acknowledge these unique features of life and start to use vital concepts both in theory and practice, which would, of course, goes against the mainstream concept of science, and would create serious contradictions between the concepts and practices of physical and life sciences-which nobody wants.

I like to emphasize that this problem is not new at all in life sciences, but almost two centuries old! Already in the middle of the 19th century several biologists tried to find a way out of this dichotomy. Or later, for example, Henri Bergson, the famous "vitalist" was, in fact, not a vitalist at all but a philosopher who tried to construct a third way, a way out of this problem. If we read his Creative Evolution, we will see that he all the way argues that neither the usual mechanical nor the vital understanding of the living machine is appropriate (Bergson 1922); still the fact that he argues against vitalism does not matter at 
all, he have became the most famous vitalist because he also does not accept the mechanical approach. After the victory of materialism over dualism in science in the first half of the 20th century, since materialists think in this dichotomy, every non-material principle becomes a vitalist one; so, if Bergson or anybody else does not accept the materialist approach, he, regardless of what he, in fact, says, can only be a vitalist.

However, the point of the problem is, of course, not solved at all; we still cannot make clear, philosophically grounded distinction between life-less machines and living machines and the very different meanings of the concept of mechanical.

\section{Alexander's solution}

According to Samuel Alexander, the only possible way out of this conceptual problem is to left behind the matter vs. mind dichotomy, which also means a departure, of course, from the materialist monism vs. dualism dichotomy. His solution is really simple; however, it is really hard to understand because we are familiar only with materialist and dualist concepts; so it requires a really hard intellectual effort to start to think in this new way.

First of all, it is not metaphysical in the narrower or scientific (negative) sense because it does not try to understand the point of the unique features of living beings based on the concept of mind; consequently, on such experiences which come form the unique features of mind and not from the unique features of life. Moreover, he does not even want to understand the point of the unique features of living beings based on the concept of matter as scientists usually do; consequently, on such experiences which come form the unique features of matter. In this sense he is even less metaphysical than modern scientists. As we will see in details in a minute, his starting point is nothing else but the experiences concerning the unique features of life. However, in the broader or philosophical (positive) sense, his approach is, of course, metaphysical, since he tries to construct a useful ontology for the understanding of the unique features of life to be able to appropriately differentiate it both from mind and matter.

So, as we have seen, according to the modern dichotomy, that if these unique features are real, that is, not material, then they will have to be mindlike, that is, not determinated and not material at all-which means that there is another, vital composite substance in living beings.

However, Alexander's starting point, on the one hand, is the existing fact of the unique features of living beings, meaning that you acknowledge this real difference as it is given in experience regardless of the consequence of any metaphysical concept of mind or matter; and his starting point, on the other hand, the existing fact that living beings are material, meaning that they are entirely composed of the same substance like machines and of nothing else because we 
cannot see any other substance. Once more, if you think in the dichotomy, this latter fact means that there is no real difference between machines and living beings because real differences are defined by composite substances, by matter and mind or some mind-like vital one.

However, Alexander is really anti-metaphysical in this sense, so he claims that there are material processes which are material in the substantial sense and which have no other unique aspects of existence (normal physical and chemical processes), and there are material processes which are material and only material in the substantial sense but which, since have some unique features, are not just material in a new sense (normal life processes). Of, course, the ontological concept which covers this new sense is his concept of emergence.

"Life is thus intermediate between matter and mind. It is also material in that it is expressible (and we may hope may be expressed hereafter) in material terms, but it is not purely material. Life is not an epiphenomenon of matter but an emergent from it. [...] The new character or quality which the vital physico-chemical complex possesses stands to it as soul or mind to the neural basis. The directing agency is not a separate existence but is found in the principle or plan of the constellation.” (Alexander 1920 II., 64)

So, this new conceptual solution is anti-metaphysical in the sense that it does not use the old metaphysical concepts of mind and matter, according to the dichotomy of mind and matter based on old historical and religious reasons, but creates a new concept based on the unique features of life given in experience. This means that both machines and living beings are mechanical,--that is, living beings are living machines,--in the sense that they are both determined by their only composite substance, structure, laws, and principles. However, there are not just material structures and laws but emergent structures and principles, too, causing the unique features of living beings. And mind is, of course, one step higher over life.

What is important to see here is that existence is not defined by the concept of substance and by the modern dichotomy between matter and mind. The fact that living beings are vital does not involve that they are mind-like in any sense, or they are composed of any matter-like other substance than matter: existence is not just matter and mind. As a matter of fact, existence in the evolutionary system of Earth is primarily life.

In the logical sense, it is clearly a possible philosophical position. Usually nobody question that; however, usually almost everybody questions that it is a real concept, that is, it is possible in the sense of reality. The main reason of this, I believe, that we do no understand how something which is composed only of matter could be an emergent living being and not just a material process, while something else which is also composed only of matter is indeed just a life-less material process. And if we think about matter, according to the matter vs. mind dichotomy, this will always be the result. Since matter in Alexander's concept is not a substance at all, in this old dichotomical sense. Matter 
is a substance only in a sense that it is the composite and only composite part of every material or living process but not a substance on its own-exactly the same way as the vital features of life are not substantial on their own and, at a more higher level, mind is also not substantial on its own, because due, by the way, to the evolutionary origin of life and mind, they are all built and depend on lower levels of reality; consequently, in the old dichotomical sense, they are not substances at all.

In Alexander's theory the concept of emergence and not the concept of composite substance covers the phenomenon of existence as it is in modern thinking. So, matter is also emergent and not the ultimate bottom of reality. It is the only composite substance of life, but not a substance on its own. This also means that matter is not defined against the concept of mind, it is not the antithesis of mind - that is, it is not inert, static, atom-like, etc., but as it has emerged form space-time, it has the potentiality in certain favourable conditions to step forward, certain movements of matter could lead to the emergence of a new higher reality called life-and similarly, life composed only of matter also has the potentiality that in certain favourable conditions in the evolutionary system of Earth and the nervous systems of living beings could lead to the rise of consciousness and mind.

And exactly this is the difference between normal material processes and vital material processes. Life is in a specific space-time, called the evolutionary system of Earth, and this specific space-time relation is the mechanical and determinate cause that the potentiality in certain material processes emerges as life. Life is defined not just by its only composite substance, matter but by its unique space-time relations with other life, with the ecosystem, and, in fact, with the whole Solar system, which we can define with such concepts and principles as species, natural selection, genes, etc. A life-less molecule or a stone is not defined by these space-time relations.

Emergence is a dynamic process; it is the movement of space-time, which unfolds the newer and newer aspects of reality-mainly matter, life, and mind. According to Alexander, the fundament of reality is not a substance, matter or mind, but emergent space-time; and the ultimate bottom of reality is an "infinite singularity" (Alexander 1920 I., 339). We are living in an evolving, dynamic universe. I think today this is a fact. However, a century earlier even the great Albert Einstein himself was horrified by the dynamic consequences of his theory of relativity and he arbitrary introduced the famous cosmological constant into his equations to save the centuries old static picture of reality. Contrary to him, Alexander pictured a dynamic universe from the infinite singularity of the first point-instant through space-time, matter, and life to mind, perhaps even further in the future, where existence is defined by this process of emergence.

The discoveries of the last century support this picture of reality. However, in philosophy and science we still use the static, substantive concepts of matter and mind defined against each other because of old historical and reli- 
gious reasons to cover all the various evolving and dynamic features of reality from space-time to consciousness. Consequently, we cannot clearly differentiate between life-less machines and living machines.

\section{Conclusion: A small Polanyian point}

To end this paper I would like to point to a mistake in Alexander's argument which was recognised and corrected by Michael Polanyi, a later emergentist. Alexander did not recognise it, I suppose, because he was not interested in this consequence of his argument at all, that there is a third meaning of mechanical beyond material and determinated. In this third case, it simply means machine. Since ordinary mechanical processes like wind or temperature are clearly not mechanical machines as ordinary life-less machines are not living machines, one can basically repeat Alexander's argument between mechanical ordinary processes and mechanical machines, too, resulting that, in fact, not just living beings are emergent compared to ordinary mechanical processes but already life-less machines are emergent to ordinary mechanical processes in a similar but not in the same way (Polanyi 1967). And actually, this is the more proper, more complete applying of the argument done first by Michael Polanyi

Therefore, living machines composed only of matter are determinated by the space-time relations of the evolutionary system of Earth, which simply means they are a part of evolution, the emergence of reality to seek higher and higher achievements, to conquer the spaces of the evolutionary system, and to dominate other species. However, life-less machines composed only of matter are determinated by the unique relations of human institutions especially of technology and economics; they are not a part of evolutionary emergence, they are planned, created, and controlled by man because of specific reasons and for specific goals. Although in a sense, we are the same, composed only of matter and determinated by our mechanical structure, still, in another (broader) sense, there is a huge difference between life-less machines by technology and living machines by emergent evolution.

However, from a mainstream point of view, this difference by emergence will vanish, and, for example, anthropomorphically we will suppose that due to the same composite substance and mechanical structure machine are able to do the same unique things as we are that they have the same unique evolutionary goals and motivations as we have, and even more anthropomorphically based on the other substantial concept of the matter and mind dichotomy - that our minds or souls are created by the image of God-we will suppose that our mechanical creatures will gain conscience and will rise up against us - as we did against God in Paradise-, and, then, we will get the so popular concept of the so-called technological singularity-and, by the way, we will not even notice that our popular concept is both based on the thesis and the antithesis of the dichotomy. 


\section{References}

Alexander, Samuel. Space, Time, and Deity. Vol. I.-II. London: MacMillan and Co., 1920.

Bergson, Henri. Creative Evolution. London: McMillan and Co., 1922.

Broad, C. D. "II.-Prof. Alexander's Gifford Lectures.” Mind XXX, no. 117 (1921a): 25-39.

Broad, C. D. “I.-Prof. Alexander's Gifford Lectures.” Mind XXX, no. 118 (1921b): 129-150.

Broad, C. D. The Mind and its Place in Nature. New York: Routledge, 1925.

Lewes, George Henry. Problems of Life and Mind. First Series. The Foundations of a Creed Vol.

II. Boston: James S. Osgood, 1975.

McLaughlin, Brian P. “The Rise and Fall of British Emergentism.” In Emergence or Reduction?

Essays on the Prospects of Nonreductive Physicalism, edited by Ansgar Beckermann, Hans

Flohr and Jaegwon Kim, 49-93. Berlin, New York: Walter de Gruyter, 1992.

Mill, John Stuart. A System of Logic. London: Harrison and Co., 1943.

Morgan, C. Lloyd. Emergent Evolution. London: Williams and Norgate, 1923.

Paksi, Daniel. Personal Reality. The Emergentist Concept of Science, Evolution, and Culture.

Volume 1 and 2. Eugene, OR: Pickwick Publications, 2019.

Polanyi, Michael. Personal Knowledge. London: Routledge and Kegan Paul, 1962.

Polanyi, Michael. “Life’s Irreducible Structure.” In Michael Polanyi: Knowing and Being: Essays, edited by Marjorie Grene, 225-39. New Brunswick: Transaction, 1969.

Stout, B. F. “The Philosophy of Samuel Alexander I.” Mind XLIX, no. 193. (1940a): 1-18.

Stout, B. F. “The Philosophy of Samuel Alexander II.” Mind XLIX, no. 194. (1940b.): 137-149. 